\title{
POLA KEBIJAKAN KPID WILAYAH RIAU DALAM MENGAWASI DIGITALISASI PENYIARAN
}

\author{
Desy Mairita, M. Tazri, Sumayah \\ Universitas Muhammadiyah Riau (UMRI), Indonesia \\ Email: desymairita@umri.ac.id, tajri@umri.ac.id, sumaiyahabdullah@gmail.com
}

\begin{abstract}
Abstrak
Penelitian ini mendeskripsikan tentang pola kebijakan KPID Wilayah Riau dalam mengawasi digitalisasi penyiaran. Di saat regulasi kita belum siap dengan segala bentuk kebebasan perstersebut, kita juga dipaksa untuk menghadapi era digitalisasi dan konvergensi yang juga memerlukan regulasi yang lebih tepat dan lugas. Meskipun di banyak sisi, regulasi kita masih memiliki kekurangan dan kurang konsisten dengan Undang-Undang pendahulunya. Tinjauan pustaka ketersediaan data pada saat ini didapatkan melalui studi pustaka dan observasi dalam bentuk bukti-bukti tempirik dalam bentuk jurnal dan buku. Metodologi dalam penelitian ini menggunakan metode deskriktif kualitatif. Penelitian ini dilakukan di Kantor KPID wilayah Riau Jl. Gajah Mada. Dengan subjek dalam penelitian ini adalah Komisioner KPID Wilayah Riau. Hasil penelitian menunjukan Hasil penelitian menunjukkan bahwa isi siaran yang baik sesuaidengan UU No.32 Tahun 2002 dan Pedoman Perilaku Penyiaran dan Standar Program Siaran Tahun 2012, namun masih ada pelanggaran yang dilakukan tetapi tergolong kepada pelanggaran yang ringan, pola pengawasan yang dilakukan KPID Riau menggunakan pola pengawasan langsung yaitu dengan memantau langsung dari alat pemantau KPID Riau yang dilakukan oleh tim pemantau, dan menggunakan polapengawasan tidak langsung yaitu dengan menerima aduan masyarakat dan dalam melakukan pengawasan KPID Riau mengikuti langkah-langkah sesuai dengan Standar Operasional Prosedur (SOP). Sedangkan KPID Riau dalam mengawasi durasi dan pola siaran di Riau mengharuskan mendaftarkans etiap acara yang akan yang ada di KPID Riau untuk mendapatkan izin siar. Untuk sarana pengawasann yang digunakan KPID Riau antara lain ruangan pengawasan, alat pemantau yang disertai dengan alatperekam dan monitor dan juga melalui situs website www.kpidriau.go.id dan media sosial email, twitter, facebook, instagram, SMS dan whatshap Kelima KPID Riau memberikan KPID award setiap tahunnya sebagai bentuk apresiasi.
\end{abstract}

Kata Kunci: Digitalisasi; KPID; Penyiaran

\section{Abstract}

This research describes the kpid strategy pattern of Riau Region in digitalization of panyan spy. At a time when we are not ready for the free form of perstersebut, we are also brothers for the era of digitalization and convergence that there are also some more precise and straightforward. Although on many sides, we are still deficient and less consistent with the Act of its predecessor. Library studies appear data at the moment post-study study library and observation in the form of evidence tempirik in the form of journals and books. The methodology in this study uses 
qualitative descriptive methods. This research was conducted at kpid office in Riau, Jl. Gajah Mada. With the subject in this study is the Commissioner kpid Riau Region. The results of the research points showed that the content of the broadcast is good with Law No.32 of 2002 and Guidelines for Broadcast Performance and Broadcast Program Standards in 2012, but there are still violations committed but classified to the minor violations, the pattern of supervision that KPID Riau uses a pattern of direct care with monitoring, and using indirect surveillance patterns that are with the good name of public complaints and in the supervision of KPID Riau operational measures Procedure (SOP). While KPID Riau in the past the duration and pattern of broadcasts in Riau remains in Riau caught every event which is in KPID Riau to get a broadcast permit. For which means of supervision that use KPID Riau, among others, surveillance, monitoring tools accompanied by tools and monitors and also sites www.kpidriau.go.id sites and social media email, twitter, facebook, instagram, SMS and whatshap Only KPID Riau awards KPID every year so a form of appreciation.

Keywords: digitization; KPID; Broadcast

\section{Pendahuluan}

Televisi (TV) adalah media penerima suara dan gambar bergerak yang paling banyak digunakan di seluruh pelosok dunia. Semua peristiwa-peristiwa besar yang terjadi di berbagai sudut dunia, dengan cepat dapat diketahui masyarakat melalui pesawat TV di manapun bahkan diberbagai belahan dunia berkat sistem penyiaranTV (television broadcasting) (Kustiawan, 2016).

Proses perkembangan penyiaran TV sudah berlangsung dalam rentang waktu yang cukup panjang. Produk teknologi modern ini juga telah tampil sebagai sarana penyebaran informasi yang cukup efektif dan relatif murah pada masyarakat luas, sehingga akan semakin berperan dalam memengaruhi pembangunan karakter bangsa. Dengan demikian penguasaan teknologi dan sistem penyiaran TV menjadi sangat strategis bagi bangsa Indonesia (Ahmad, 2015).

Dengan begitu pesatnya perkembangan teknologi digital, yang memberikan kontribusi dominan terhadapi bidang penyiaran, telekomunikasi dan teknologi informasi, memungkinkan siaran TV berkualitas gambar yang tinggi dapat dinikmati para pemirsa berbagai perangkat seperti telepon gengam (handphone), PDA (personal digital assistant), komputer, maupun media TV yangtak bergerak (fixed) dan bergerak (mobile). Berdasarkan pengalaman negara lain yang telah mengganti sistem penyiaran TV-nya ke teknologi digital, perubahan tersebut telah menyebabkan terjadinya perubahan model bidang usaha dan meningkatnya layanan konten serta optimasi penggunaan kanal frekuensi, sehingga migrasi sistem penyiaran TV analog ke sistem penyiaran TVdigital, akan sangat bermanfaat bagi pemerintah, masyarakat maupun industri (Wahyuni, 2018).

Penyiaran Digital menjadi sebuah keniscayaan, dan dianggap sebagai solusi untuk mengatasi keterbatasan dan ketidak efisienan penyiaran analog. Seperti yang diketahui, teknologi analog tidak dapat mengimbangi permintaan industry penyiaran dalam hal penyaluran program siaran yang terus bertambah karena terbatasnya jumlah kanal 
frekuensi yang tersedia. Selain itu juga, penggelaran infrastruktur penyiaran analog pun tidak efisien karena belum menyentuh konvergensi. Dalam suatu system penyiaran analog, masing-masing lembaga penyiaran memiliki infrastruktur penyiarannya sendirisendiri, seperti menara pemancar, antena, dan lain sebagainya. Akibatnya, biaya pemeliharaan cenderung relatif mahal, pemakaian daya listrik yang sangat besar, serta pemanfaatan lahan yang jauh lebih boros. Di sisi penerimaan siaran pun, kualitas siarannya tidak akan merata meski berada dalam wilayah layanan yang sama (Rianto, 2012).

Di dalam UU Nomor 32 tahun 2002 tentang penyiaran telah diatur pasal pasal tentang isi siaran, pasal 35 dan 36 jadi sangat diharapkan bahwa lembaga penyiaran mematuhi aturan-aturan yang telah ditetapkan, tetapi pada kenyataannya masih banyak lembaga penyiaran yang melanggaraturan-aturan yang sudah disepakati bersama (Bunga Indriani Nst, Rum, \& Katutu, 2019). Menurut undang-undang No. 32 tahun 2002 ini terdapat tujuan penyiaran:

1) Untuk memperkukuh integrasi nasional.

2) Terbinanya watak dan jati diri bangsa yang beriman dan bertaqwa.

3) Mencerdaskan kehidupan bangsa.

4) Memajukan kesejahteraan umum.

5) Menumbuhkan industry penyiaran Indonesia

Dalam system pengawasan penyiaran, Riau telah memiliki Komisi Penyiaran Indonesia Daerah Riau (KPID Riau) yang bertugas sebagai pengawas penyiaran yang ada di daerah provinsi Riau itu sendiri. Komisi Penyiaran Indonesia Daerah Riau juga berhubungan dengan masyarakat dalam menampung segala hal dan menindak lanjuti segenap apresiasi masyarakat terhadap lembaga penyiaran maupun terhadap dunia penyiaran pada umumnya. Dalam melaksanakan dan menjalankan fungsi serta tugas, wewenang dan kewajibannya Komisi Penyiaran Indonesia Pusat diawasi oleh Dewan Perwakilan Rakyat Republik Indonesia, dan Komisi Penyiaran Indonesia Daerah diawasi oleh Dewan Perwakilan Rakyat Daerah itu sendiri (Sambodo \& Ishak, 2017). Dalam menjalankan fungsinya Komisi Penyiaran Indonesia mempunyai kewewenang:

1) Menetapkan standar program siaran

2) Menyusun peraturan dan menetapkan pedoman perilaku penyiaran

3) Mengawasi pelaksanaan peraturan dan pedoman perilaku penyiaran

4) Memberikan sanksi terhadap pelanggar peraturan dan pedoman perilaku penyiaran dan standar program siaran

5) Melakukan koordinasi dengan pemerintah, lembaga siaran dan masyarakat KPID Riau mengawasi penyiaran baik itu siaran radio maupun siaran TV lokal.

Kebutuhan teknologi digital sangat tepat mengatasi jumlah alokasi kanal analog yang terbatas, sementara minat masyarakat berpartisipasi begitu kuat. Sehingga jalan alternatif penerapan siaran televisi digital di Indonesia merupakan satu solusi keterbatasan kanal tersebut. Dengan adanya siaran sistem digital tersebut, beberapa stasiun penyiaran swasta dapat bergabung dalam penyiarannya dengan satu kanal digital yang diberikan oleh pemerintah (Budiman, 2016). 
Pesatnya pertumbuhan teknologi informasi dan komunikasi berdampak terhadap konvergensi antara industri penyiaran dan telekomunikasi atau yang lebih dikenal sebagai "konvergensi media" (media convergence). Industri penyiaran, para pengusaha media menyediakan konten-konten penyiaran ke dalam format digital atau aplikasi berbasis mobile seperti e-paper dan online streaming. Berdasarkan uraian diatas, penulis tertarik untuk mengadakan penelitian dengan rjudul "Pola Kebijakan Komisi Penyiaran Indonesia Wilayah Riau dalam Mengelola Digitalisasi Penyiaran" (Sa'diyah El Adawiyah \& Swarnawati, 2015).

Di saat regulasi kita yang belum siap dengan segala bentuk kebebasan pers tersebut, kita juga dipaksa untuk menghadapi era digitalisasi dan konvergensi yang juga memerlukan regulasi yang lebih tepat dan lugas. Meskipun di lain sisi, regulasi kita masih memiliki banyak kekurangan dan tidak konsisten dengan Undang-Undang pendahulunya. Oleh kerenanya, ini merupakan suatu permasalahan dalam penyiran dan menarik untuk diteliti. Maka permasalahan dalam penelitian ini adalah bagaimana pola kebijakan KPID wilayah Riau dalam mengawasi Digitalisasi Penyiaran.

\section{Metode Penelitian}

Penelitian ini menggunakan pendekatan penelitian kualitatif, yaitu suatu metode penelitian yang digunakan untuk meneliti pada kondisi objek yang alamiah, dimana peneliti adalah sebagai instrumen kunci. Dalam hal ini peneliti berupaya melakukan deskripsi tentang pola kebijakan KPID Wilayah Riau dalam mengawasi digitalisasi penyiaran. Penelitian ini dilakukan di Kantor KPID wilayah Riau Jl. Gajah Mada. Dengan subjek dalam penelitian ini adalah Komisioner KPID Wilayah Riau. Objek penelitian dapat dinyatakan sebagai situasi sosial penelitian yang ingin diketahui apa yang terjadi di dalamnya. Pada obyek penelitian ini, peneliti dapat mengamati secara mendalam aktivitas (activity) orang-orang (actors) yang ada pada tempat (place) tertentu (Gumilang, 2016).

Yang menjadi objeknya dalam penelitian ini adalah pola kebijakan KPID Wilayah Riau dalam Mengawasi Digitalisasi Penyiaran. Dalam penelitian kualitatif, tidak menggunakan istilah populasi ataupun sampel seperti dalam penelitian kuantitatif. Dalam penelitian kualitatif, populasi diartikan sebagai wilayah generalisasi yang terdiri atas obyek/subyek yang mempunyai kualitas dan karakteristik tertentu yang ditetapkan oleh peneliti untuk dipelajari dan kemudian ditarik kesimpulannya. Sedangkan sampel adalah sebagian dari populasi itu (Sugiyono, 2008).

Oleh karena itu, peneliti akan menggunakan informan untuk memperoleh berbagai informasi yang dipelukan selama proses penelitian. Informan penelitian dipilih berdasarkan teknik snowball yaitu dengan mencari informan kunci. Yang dimaksud dengan informan kunci (key informan) adalah mereka yang mengetahui dan memiliki berbagai informasi pokok yang diperlukan dalam penelitian atau informan yang yang mengetahui secara mendalam permasalahan yang sedang diteliti. Berdasarkan penjelasan tersebut, maka yang menjadi informan kunci dalam penelitian ini komisioner KPID wilayah Riau. Menurut Lopland dalam Buku Metodologi Penelitian Kualitatif 
dijelaskan bahwa sumber data utama dalam penelitian kualitatif ialah kata-kata dan tindakan (Fauzia, 2020).

Data apabila digolong menurut asal sumbernya dapat dibagi menjadi dua kategori yaitu data primer dan data sekunder. Data primer adalah data yang diperoleh langsung dari objek yang akan diteliti (responden). Data primer dalam penelitian ini adalah data yang diperoleh langsung dari objek yang akan diteliti (komisioner KPID wilayah Riau) sedangkan data sekunder adalah data yang diperoleh dari lembaga atau instansi tertentu, seperti biro pusat statistic dan lain-lain (Fauzia, 2020). Teknik pengumpulan Data dalam penelitian ini yaitu dengan cara Interview, Observasi dan dokumentasi. Setelah data terkumpul, kemudian dilakukan pengelolaan data tersebut yang disesuaikan dengan kebutuhan analisis yang akan dikerjakan. Analisis yang digunakan adalah analisis studi kasus dimana studi kasus itu adalah suatu strategi dan metode analisis data kualitatif yang menekankan pada kasus-kasuskhusus yang terjadi pada objek analisis (Bungin, 2011) dan ini menyangkut masalah perkembangan objek, sejarah dan struktur fenomona. Uji Keabsahan Data yang digunakan dalam penelitian ini adalah Credibility (derajat kepercayaan) dengan cara triangulasi. Menurut (Pritandhari, 2016), trianggulasi adalah teknik pemeriksaan keabsahan data yang memanfaatkan sesuatu yang lain.

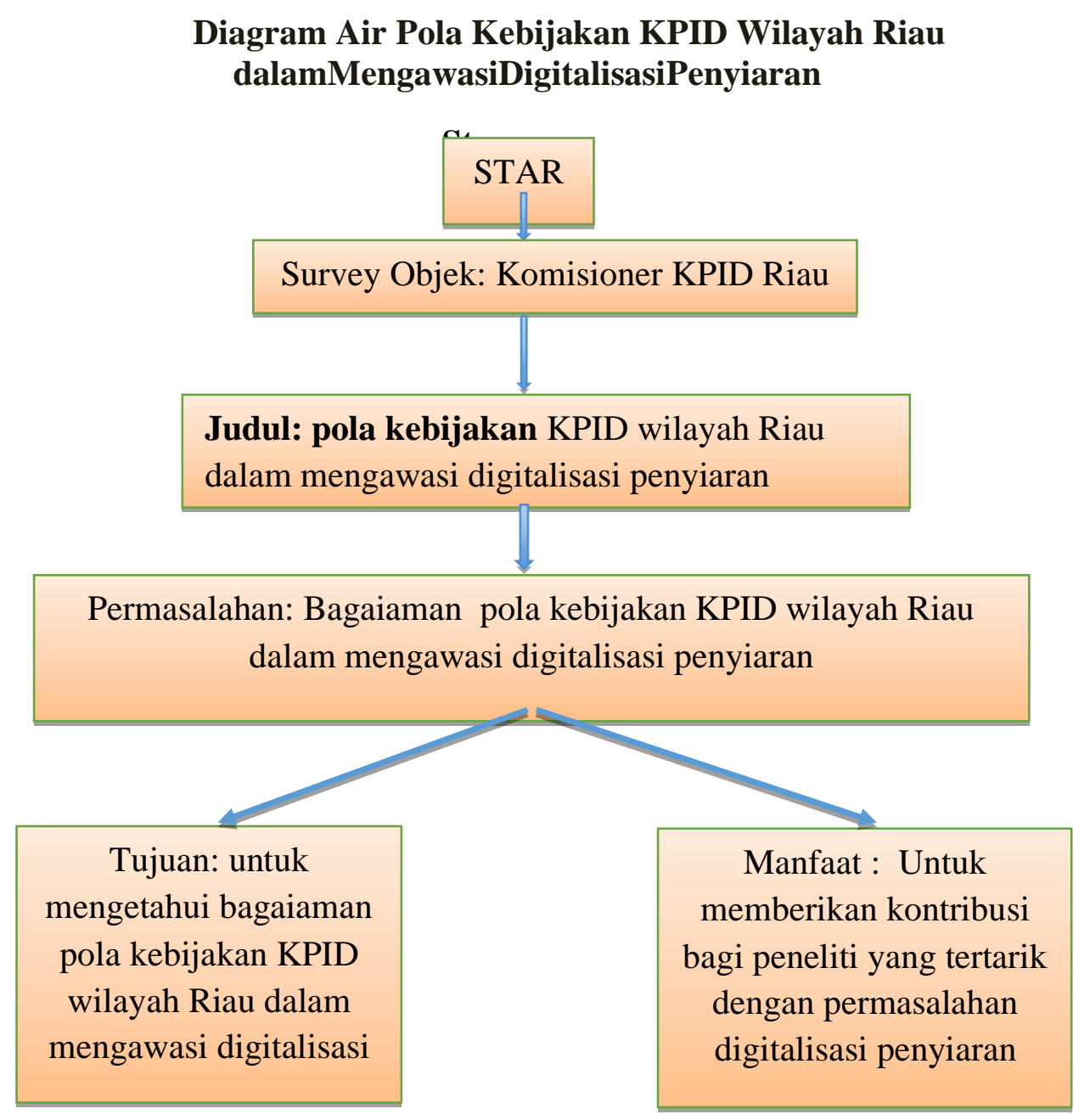


Desy Mairita, M. Tazri, Sumayah

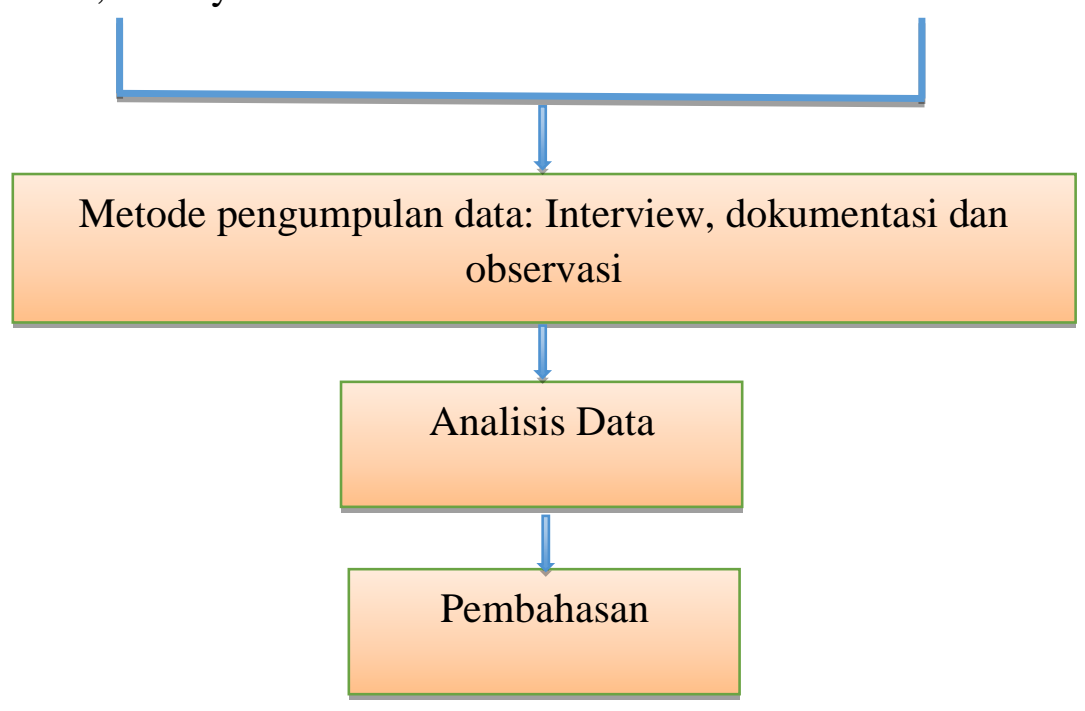

\section{Hasil dan Pembahasan}

Perubahan dari televisi analog ke televisi di pengaruhi oleh perkembangan teknologi informasi dan komunikasi termasuk dengan melihat perubahan pengguna internet di dunia yang terus meningkat. Pada tahun 2002 pengguna internet diperkirakan mencapai 605.6 miliar jiwa. Di Indonesia, menurut data Asosiasi Penyelenggara Jasa Internet Indonesia (APJII), jumlah pengguna internet pada tahun 2013 mencapa 71,19 juta, meningkat 13 persen dibandin tahun 2012 yang mencapai sekitar 63 juta pengguna (Nurudin, 2018). Dari data yang telah dipublikasikan oleh Kominfo pada laman web mereka menunjukan Indonesia berada di posisi keenam jumlah total pengguna internet yaitu sebesar 102,8 juta Perkembangan dari televisi digital memperoleh kritik, bahwa dalam proses ini tidak diberikan spektrum bagi pemain baru. Padahal pemain baru diharapkan dapat lebih mampu mengembangkan inovasi yang berbeda dalam jasa yang ditawarkan. Hal ini, kebijakan yang ada lebih kepada membatasi kompetisi. Televisi digital berdasarkan Permen Kemenkominfo No. 22/2011 tidak memiliki aturan yang kuatmengenaiizinpenyiaran, sertatidakmelibatkan KPI dan KPID didalamnya. Regulasi penyiaran digital dimulai tahun 2007 melalui Permen Kemenkominfo. Kemudian, telah disusul dengan beberapa peraturan menteri lainnya. Adapun perkembangan regulasi dalam proses digitalisasi di Indonesia dilihat dalam tabel di bawah ini.

\section{Tabel 1}

Perkembangan Regulasi Dalam Proses Digitaliasai Di Indonesia

Regulasi Isi Siaran

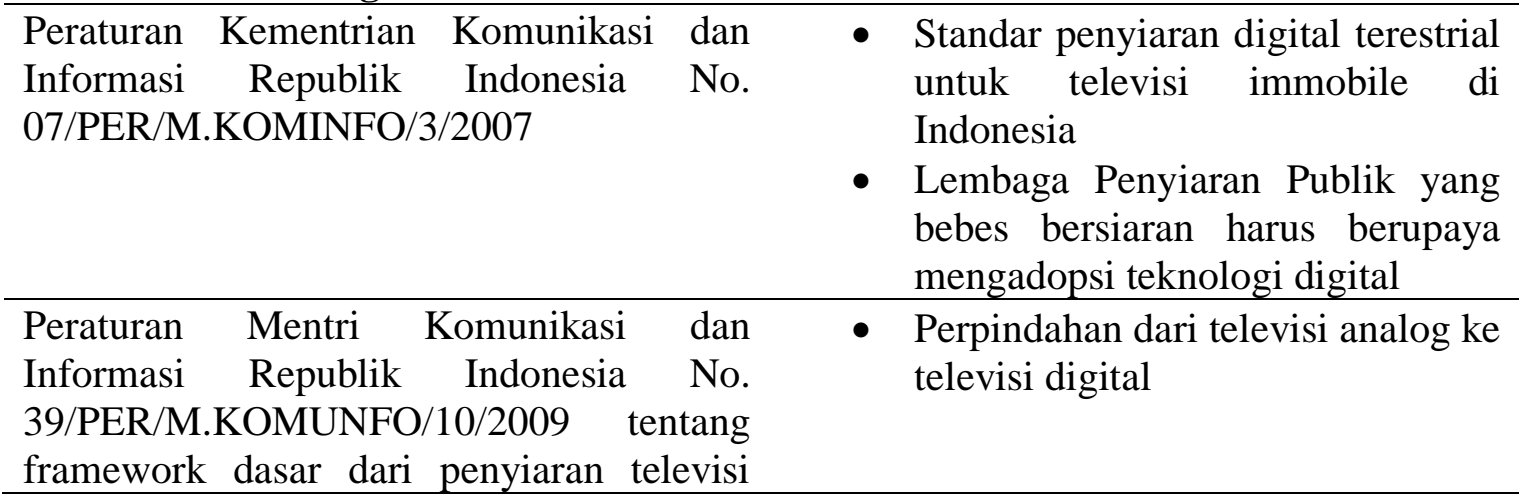




\begin{tabular}{|c|c|}
\hline Regulasi & Isi Siaran \\
\hline $\begin{array}{l}\text { digital teristrial untuk secara bebas mengisi } \\
\text { dengan penerimaan yang permanen (free- } \\
\text { to-air) }\end{array}$ & \\
\hline $\begin{array}{lccc}\text { Peraturan } & \text { Kementrian } & \text { Komunikasi } & \text { dan } \\
\text { Informasi } & \text { Republik } & \text { Indonesia } & \text { No. } \\
\text { 21/PER/M.KOMINFO/4/2011 } & \end{array}$ & $\begin{array}{l}\text { - Standar penyiaran digital bagi } \\
\text { radio dengan Very High } \\
\text { Frequency (VHF) band di } \\
\text { Indonesia }\end{array}$ \\
\hline
\end{tabular}

Dalam Perkembangannya saat ini, pemerintah melalui Kementerian Komunikasi dan Informatika telah menerbitkan Peraturan Menteri No. 5 Tahun 2016 tentang Uji Coba Teknologi Telekomunikasi, Informatika dan Penyiaran. Konsideran regulasi tersebut 2 adalah dalam rangka penelitian dan penetapan arah kebijakan penyelenggaraan telekomunikasi, informatika dan penyiaran. Beberapa jenis teknologi yang berkembang dan perlu dilakukan uji coba diantaranya open BTS, Google Loon, PPDR (public Protection and Disaster Relief), 5G, TV digital metode SFN (single frequency network) dan MFN (multi frequency network). Ujicoba yang dilakukan tersebut cukup membingungkan baik bagi publik maupun bagi pelaku bisnis. Sebab, selama ini pemerintah belum menyelesaikan urusan regulasi penyiaran digital yang seharusnya dibuat dalam bentuk UU, tetapi pemerintah lebih memilih untuk melakukan berbagai uji coba siaran yang dikawatirkan proses ini nantinya sama sekali berbeda saat digitalisasi penyiaran disahkan (Nurudin, 2018).

Dalam rangka untuk mewujudkan visi Komisi Penyiaran Indonesia Daerah Riau yaitu : "Terwujud Sistem Penyiaran yang Sehat, Adil dan Berkualitas di Provinsi Riau", maka perlukiranya Komisi Penyiaran Indonesia Daerah Riau untuk melakukan pengawasan yang lebih intensif.

Pengelolaan sistem penyiaran yang merupakan ranah publik harus dikelola oleh sebuah badan independen yang bebas dari campur tangan pemodal maupun kepentingan kekuasaan. Untuk tercapainya siaran yang berkualitas bagi masyarakat dan mempermudah pendirian perizinan bagi dunia usaha di bidang penyiaran serta kontrol terhadap siaran yang akan diberikan kepada masyarakat di Provinsi Riau, maka pada tahun 2010 terbentuklah Komisi Penyiaran Indonesia Daerah Riau (KPID Riau) (Rusli \& Zulkarnaen, 2014). Kemudian untuk menunjang kinerja KPID Provinsi Riau maka dibentuklah Sekretariat KPID Provinsi Riau sesuai amanat Peraturan Daerah Provinsi Riau Nomor 7 Tahun 2012 tentang Pembentukan Sekretariat Komisi Penyiaran Indonesia Daerah Provinsi Riau, yang rincian tugasnya diatur dalam Peraturan Gubenur Riau Nomor 48 Tahun 2015 tentang Rincian, Tugas, Fungsi dan Tata kerja Sekretariat Komisi Penyiaran Indonesia Daerah Provinsi Riau. Sehingga keseriusan Pemerintah Provinsi Riau dalam mengelola penyiaran dibuktikan melalui lahirnya peraturan daerah dan peraturan gubernur tersebut Dalam melaksanakan fungsi, wewenang, tugas dan kewajibannya, KPID Provinsi Riau terdiri atas beberapa bidang yaitu :

a. BidangPengelolaanStruktur dan SistemPenyiaran

b. BidangPengawasan Isi Siaran

c. BidangKelembagaan 
Dari ketiga bidang di atas, peneliti menitik beratkan pada Bidang Pengelolaan Struktur dan Sistem Penyiaran serta Bidang Pengawasan Isi Siaran, dimana salah satu tupoksi bidangt ersebut adalah melakukan pengawasan. Pasal 4 Peraturan KPI Nomor 01/P/KPI/07/2014 yang berbunyi, dalam melaksanakan fungsi, wewenang, tugas, dan kewajibannya, Bidang Pengelolaan Struktur dan Sistem Penyiaran KPID Provinsi Riau menyelenggarakan koordinasi, mengawasi, dan mengevaluasi program dan kegiatan

1) Perizinan lembaga penyiaran sesuai peraturan perundang-undangan yang berlaku;

2) Yang berkaitan dengan penjaminan kesempatan masyarakat memperoleh informasi yang layak dan benar sesuai dengan hak asasi manusia

3) Yang berkaitan dengan pengaturan infrastruktur penyiaran; dan

4) Pembangunan iklim persaingan yang sehat antarlembaga penyiaran dan industri terkait. Selain itu, dalam melaksanakan fungsi, wewenang, tugas, dan kewajibannya, Bidang Pengawasan Isi Penyiaran KPID Provinsi Riau juga menyelenggarakan koordinasi, mengawasi, dan mengevaluasi program dan kegiatan: Mengacu pada tupoksi kedua bidang diatas, pelaksanaan pengawasan merupakan tupoksi dari KPID Riau yang dilaksanakan melalui pengawasan

5) Pengawasan Langsung Pengawasan langsung KPID Riau dilaksanakan melalui Pengelolaan Struktur dan Sistem Penyiaran serta Bidang Pengawasan Isi Siaran, dimana kedua bidang tersebut melakukan pengawasan langsung ke kantor atau studio lembaga penyiaran yang terindikasi bermasalah, seperti perizinan lembaga penyiaran yang akan berkahir, perizinan lembaga penyiaran yang telah berkahir, ataupun lembaga penyiaran yang belum memiliki perizinan, serta pengawasan langsung isi siaran dari lembaga penyiaran

6) Pengawasan Tidak Langsung Pengawasan tidak langsung KPID Riau dilaksanakan melalui Tim Pengawasan Reguler yang terdiri dari 13 orang Tenaga Harian Lepas (THL), yang ditempatkan di ruang monitoring Sekretariat KPID Riau. Tim Pengawasan Reguler tersebut melaksanakan pengawasan terhadap konten isi siaran yang disiarkan oleh lembaga penyiaran. Apabila ditemukan konten atau isi siaran yang terindikasi dalam pelanggaran penyiaran, maka konten tersebut dicatat oleh tim dan dilaporkan kepada Bidang Pengawasan Isi Siaran untuk selanjutnya dilakukan tindak lanjut atas temuan pelanggaran tersebut. Provinsi Riau sebagai provinsi yang sedang dalam perkembangan dan pembangunan tidak luput dari aktivitas penyiaran. Aktivitas penyiaran tersebut sangat berkembang pesat, yang ditandai berdirinya berbagai lembaga penyiaran seperti TVRI, RRI, Riau Televisi, Riau Channel dan lembaga penyiaran lainnya. Hal ini dapat dilihat pada jumlah lembaga penyiaran di Riau

\section{Kesimpulan}

Pola Kebjakan KPID dalam mengawasi digitalisasi penyiaran adalah sebagai berikut. Ada 2 jenis pengawasaan yang dilakukan oleh KPID dalam melakukan pengawasan. 1) Pengawasan langsung adalah pengawasan yang dilakukan apabila pimpinan organisasi melakukan sendiri pengawasan terhadap kegiatan yang sedang dijalankan. Dalam penelitian ini pengawasan langsung yang dilakukan Komisi 
Penyiaran Indonesia Daerah Riau dilihat dari 3 (tiga) bentuk, yaitu: inspeksi langsung, observasi di tempat (The-spot observation), dan membuat laporan di tempat (On-thespot report). Inspeksi langsung merupakan kegiatan yang dilakukan untuk mengetahui dan memeriksa secara langsung kebenaran yang terjadi di lapangan. 2) Pengawasan tidak langsung adalahmerupakan pengawasan dari jarak jauh. Pengawasan yang ini dilakukan melalui laporan yang disampaikan oleh para bawahan, pihak yang diawasi, dan oleh masyarakat yang terkena dampak pengawasan. Laporan yang didapat berbentuk: laporan tertulis, laporan lisan, dan laporan khusus. Laporan tertulis merupakan suatu bentuk pertanggungjawaban lembaga penyiaran kepada pihak Komisi Penyiaran Indonesia Daerah Riau atas pelaksanaan kegiatan penyiaran melalui laporan tertulis .Hasil penelitian menunjukkan bahwa isi siaran yang baik sesuaidengan UU No.32 Tahun 2002 dan Pedoman Perilaku Penyiaran dan Standar Program Siaran Tahun 2012, namun masih ada pelanggaran yang dilakukan tetapi tergolong kepada pelanggaran yang ringan, pola pengawasan yang dilakukan KPID Riau menggunakan pola pengawasan langsung yaitu dengan memantau langsung dari alat pemantau KPID Riau yang dilakukan oleh tim pemantau, dan menggunakan polapengawasan tidak langsung yaitu dengan menerima aduan masyarakat dan dalam melakukan pengawasan KPID Riau mengikuti langkah-langkah sesuai dengan Standar Operasional Prosedur (SOP). Sedangkan KPID Riau dalam mengawasi durasi dan pola siaran di Riau mengharuskan mendaftarkans etiap acara yang akan yang ada di KPID Riau untuk mendapatkan izin siar. Untuk sarana pengawasann yang digunakan KPID Riau antara lain ruangan pengawasan, alat pemantau yang disertai dengan alatperekam dan monitor dan juga melalui situs website www.kpidriau.go.id dan media sosial email, twitter, facebook, instagram, SMS dan whatshap Kelima KPID Riau memberikan KPID award setiap tahunnya sebagai bentuk apresiasi. 
Desy Mairita, M. Tazri, Sumayah

\section{BIBLIOGRAFI}

Ahmad, Nur. (2015). Radio Sebagai Sarana Media Massa Elektronik. AT-TABSYIR STAIN Kudus, 3(2).Google Scholar

Budiman, Ahmad. (2016). Model Pengelolaan Digitalisasi Penyiaran di Indonesia. Jurnal Politica Dinamika Masalah Politik Dalam Negeri Dan Hubungan Internasional, 6(2).Google Scholar

Bunga Indriani Nst, Ipt121295, Rum, Muhammad, \& Katutu, Buchari. (2019). Upaya Komisi Penyiaran Indonesia Daerah (Kpid) Provinsi Jambi Dalam Menerapkan Informasi Berdasarkan Pedoman Perilaku Penyiaran Standar Program Siaran (P3sps) Di Kota Jambi. Uin Sulthan Thaha Saifuddin. Google Scholar

Bungin, Burhan. (2011). Metodologi Penelitian Kuantitatif, Ed.2. Jakarta: Kencana,. Google Scholar

Fauzia, Reka Resti. (2020). Strategi Komunikasi Balai Rehabilitasi Sosial Pada Kegiatan Bimbingan Karier Untuk Meningkatkan Life Skill Bagi Penyandang Disabilitas Netra. Universitas Komputer Indonesia. Google Scholar

Gumilang, Galang Surya. (2016). Metode penelitian kualitatif dalam bidang bimbingan dan konseling. Jurnal Fokus Konseling, 2(2). Google Scholar

Kustiawan, Usep. (2016). Pengembangan media pembelajaran anak usia dini. Penerbit Gunung Samudera [Grup Penerbit PT Book Mart Indonesia]. Google Scholar

Nurudin, Ade. (2018). Digitalisasi Penyiaran Indonesia Dalam Bingkai Kepentingan Publik. Source: Jurnal Ilmu Komunikasi, 2(3). Google Scholar

Pritandhari, Meyta. (2016). Penerapan Komik Strip Sebagai Media Pembelajaran Mata Kuliah Manajemen Keuangan Mahasiswa Universitas Muhammadiyah Metro. PROMOSI: Jurnal Program Studi Pendidikan Ekonomi, 4(2). Google Scholar

Rianto, Fuji DKK. (2012). Digitalisasi Televisi di Indonesia (Ekonomi Politik, Peta Persoalan, dan Rekomendasi Kebijakan). PR2 Media bekerja sama dengan Yayasan Tifa: Yogyakarta. Google Scholar

Rusli, Zaili, \& Zulkarnaen, Deddy. (2014). Efektivitas Pengawasan Penyiaran Tv Kabel Berlangganan oleh KPID Riau. Riau University. Google Scholar

Sa'diyah El Adawiyah, Suwarto, \& Swarnawati, Aminah. (2015). Hubungan Media Baru dengan Sikap Nasionalisme Remaja di DKI Jakarta. Information and Communication Technology, 95. Google Scholar

Sambodo, Satria, \& Ishak, Ishak. (2017). Pengawasan Komisi Penyiaran Indonesia Daerah Riau Terhadap Penyelenggaraan Penyiaran TV Kabel Di Pekanbaru Tahun 2015-2016. Riau University. Google Scholar 
Pola Kebijakan KPID Wilayah Riau dalam Mengawasi Digitalisasi Penyiaran

Sugiyono. (2008). Metode Penelitian Kunatitatif Kualitatif dan R\&D. Bandung Alfabeta. Google Scholar

Wahyuni, Hermin Indah. (2018). Kebijakan Media Baru Di Indonesia:(Harapan Dinamika Dan Capaian Kebijakan Media Baru Di Indonesia). Ugm Press. Google Scholar

\section{Copyright holder :}

Desy Mairita, M.Tazri, Sumayah (2021)

First publication right :

Syntax Idea

This article is licensed under:

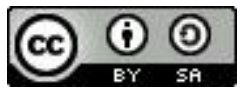

